\title{
Sikap Masyarakat terhadap Program Peningkatan dan Pengembangan Pertanian Perkotaan (Urban Farming) di Kecamatan Jebres Kota Surakarta
}

\section{People's Attitude Towards Urban Agriculture Improvement and Development Program (Urban Farming) In Jebres Subdistrict, Surakarta City}

Danik Ayu Prasetyo, Eny Lestari, Bekti Wahyu Utami

\author{
Program Studi Penyuluhan dan Komunikasi Pertanian, Fakultas Pertanian \\ Universitas Sebelas Maret Surakarta \\ J1.Ir. Sutami No.36 A Kentingan Surakarta 57126 Telp./Fax (0271) 637457 \\ Email: danikap54@gmail.com
}

\begin{abstract}
This study aims to analyze people's attitudes towards the urban farming program, identifying factors that shape people's attitudes towards urban farming programs, analyzing the relationship between attitudeforming factors and people's attitudes towards urban farming programs. This study uses quantitativemethods with descriptive analysis and survey techniques. The location of the study was carriedout in Jebres Subdistrict. The study sample was 70 people taken by proportional random sampling.The data sources used in this study are primary and secondary. The data analysis that used is Rank Kendall. The results showed that:(1) the factors forming the attitude are characteristics of individuals (age majority at age 15-64 years/ the productive age category, majority high school education), personal experience in the medium category, family influence in the high category, reference group in the sufficient category, exposure to mass media in the medium category, and culture in the high category.(2) People's attitude towards the program objectives in the agreed category, the implementation of the program in the neutral category and the program results in the agreed category. (3) There is a significant relationship between personal experience, reference groups, exposure to mass media and culture to urban farming programs. While individual characteristics and family influences have no significant relationship with people's attitudes toward urban farming programs.
\end{abstract}

Keywords: Attitude, People, Urban Farming.

\begin{abstract}
Abstrak: Penelitian ini bertujuan untuk menganalisis sikap masyarakat terhadap program urban farming, mengidentifikasi faktor-faktor pembentuk sikap masyarakat terhadap program urban farming, menganalisis hubungan antara faktor pembentuk sikap dengan sikap masyarakat terhadap program urban farming. Lokasi penelitiandilakukan di Kecamatan Jebres dengan jumlah sampel sebanyak 70 orang yang diambil secara proportional random sampling. Sumber data yang digunakan dalam penelitian ini yaitu primerdan sekunder. Analisis data menggunakan uji rank kendall. Hasil penelitian menunjukkan: (1) karakteristik individu (umur mayoritas pada usia 15 - 64 tahun, pendidikan mayoritas SLTA), pengalaman pribadi dalam kategori sedang, pengaruh keluarga dalam kategori tinggi, kelompok acuan dalam kategori cukup, terpaan media massa dalam kategori sedang, dan budaya dalam kategori tinggi. (2) Sikap masyarakat terhadap tujuan program dalam kategori setuju, pelaksanaan program dalam kategori netral dan hasil program termasuk dalam kategori setuju. (3) Terdapat hubungan yang signifikan antara pengalaman pribadi, kelompok acuan, terpaan media massa dan budaya terhadap program urban farming. Sedangkan karakteristik individu dan pengaruh keluarga tidak memiliki hubungan yang signifikan dengan sikap masyarakat terhadap program urban farming.
\end{abstract}

Kata Kunci: Masyarakat, Pertanian Perkotaan, Sikap. 


\section{PENDAHULUAN}

Pengembangan pertanian yang telah dilaksanakan masih terbatas pada penanganan lahan sawah, sedangkan untuk pengoptimalan lahan pekarangan belum banyak mendapat perhatian. Lahan pekarangan dapat menjadi agroekosistem yang sangat baik serta mempunyai potensi yang besar dalam mencukupi kebutuhan hidup masyarakat, bahkan kalau dikembangkan secara baik akan dapat bermanfaat lebih jauh lagi, seperti dapat mensejahterakan masyarakat sekitar, pemenuhan kebutuhan pasar bahkan dapat memenuhi kebutuhan nasional. Pertanian kota menjadi suatu kegiatan untuk meningkatkan pemanfaatan ruang minimalis khususnya lahan pekarangan di perkotaan melalui pembudidayaan tanaman, ikan atau ternak, yang masih dapat diterima oleh masyarakat setempat. Kondisi yang serba berbeda dengan pusat produksi pangan di pedesaan telah menginspirasi masyarakat perkotaan untuk mengembangkan model pertanian yang unik dan sesuai dengan lingkungan perkotaan (Widyawati, 2013).

Salah satu program yang dilaksanakan oleh Dinas Pertanian Kota Surakarta adalah Peningkatan dan Pengembangan Pertanian Perkotaan. Program ini mempunyai dua pokok kegiatan didalamnya yaitu untuk ketahanan pangan dan intensifikasi lahan pekarangan. Kedua kegiatan tersebut digunakan untuk mengefektifkan penggunaan lahan pekarangan yang dimiliki masyarakat Kota Surakarta. Adanya pengoptimalan lahan pekarangan di perkotaan sangat berguna untuk pengembangan pertanian yang diharapkan dapat menambah dan mengatasi kebutuhan pangan lokal penduduk kota (Departemen Pertanian, 2006).

Kecamatan Jebres merupakan salah satu wilayah yang melaksanakan program urban farming dari Dinas Pertanian dan Ketahanan Pangan Kota Surakarta. Kecamatan Jebres memiliki luas wilayah sebesar $12,58 \mathrm{~km}^{2}$ dan terdiri dari 11 Kelurahan. Kecamatan Jebres digunakan sebagai lokasi penelitian berdasarkan potensi wilayah yang dimiliki serta memiliki luas tegalan yang paling luas seKota Surakarta.Pada awal program masyarakat sangat tertarik untuk menjalankan program urban farming. Namun hampir 12 tahun berjalannya program tersebut banyak juga masyarakat yang mulai tidak aktif menjalankan program.Hal tersebut disebabkan oleh letak Kecamatan Jebres yang berada diperkotaan sehingga masyarakat disibukkan dengan berbagai macam pekerjaan pokok mereka dan pertanian perkotaan hanya untuk pekerjaan sampingan saja serta semakin sempitnya lahan karena digunakan untuk pemukiman.Sikap sebagai kecenderungan evaluatif terhadap suatu obyek atau subyek yang memiliki konsekuensi, yakni bagaimana seseorang berhadapan dengan obyek sikap (Hawkins et al, 1999). Suatu program akan berjalan optimal ditentukan oleh sikap sasaran itu sendiri. Sikap ini tidak hanya ditentukan oleh masyarakat saja melainkan proses ini juga dipengaruhi oleh faktorfaktor diluar itu.

\section{METODE PENELITIAN}

Penelitian ini menggunakan metode kuantitatif dengan analisis deskriptif danteknik survei. Penarikan sampel mengunakan metode proportional random sampling, sebanyak 70 orang yang melaksanakan program urban farming. Sumber data yang digunakan dalam penelitian ini yaitu primer dan sekunder. Teknik pengumpulan data dilakukan dengan cara wawancara, kuisioner dandokumentasi. Kuesioner merupakan teknik pengumpulan data yang dilakukan dengancara memberi seperangkat pertanyaan atau pernyataan tertulis kepada responden untukdijawabnya (Sugiyono, 2013). Analisis data guna untuk menguji derajat hubungan antara faktor pembentuk sikap masyarakatterhadap program urban farming yaitu menggunakan analisis korelasi Rank Kendall dan uji t untuk menguji tingkat signifikasinya.

\section{HASIL DAN PEMBAHASAN}

\section{Faktor-Faktor Pembentuk Sikap Masyarakat}

Sikap masyarakat terhadap program urban farming dipengaruhi oleh beberapa faktor.Faktor pembentuk sikap masyarakat disajikan dalam data deskriptif. Data ini dipergunakan untuk menggambarkan kondisi responden dan sebagai informasi tambahan dalam memahami hasil penelitian. Faktor pembentuk sikap masyarakat yang digunakan dalam penelitian ini karakteristik individu, pengalaman pribadi, pengaruh keluarga, kelompok acuan, media massa dan budaya. 
Tabel 1. Distribusi Responden Berdasarkan Umur

\begin{tabular}{lcccc}
\hline & \multirow{2}{*}{ Kategori } & \multicolumn{3}{c}{ Distribusi } \\
\cline { 3 - 4 } & & Skor & Responden & Persentase (\%) \\
\hline$>64$ tahun & 1 & 8 & 11,43 \\
$\mathbf{1 5}-\mathbf{6 4}$ tahun & Jumlah & $\mathbf{2}$ & $\mathbf{6 2}$ & $\mathbf{8 8 , 5 7}$ \\
\hline \multicolumn{2}{c}{} & & $\mathbf{7 0}$ & $\mathbf{1 0 0 , 0 0}$ \\
\hline
\end{tabular}

Berdasarkan pada Tabel 1. responden dalam penelitian ini mayoritas termasuk dalam usia produktif $(15-64$ tahun) yaitu sejumlah 62 responden atau 88,57 persen dan sejumlah 8 responden termasuk dalam kategori usia non produktif (> 64 tahun) atau 11,43 persen. Umur

Tabel 2. Distribusi Responden Berdasarkan Pendidikan Formal

\begin{tabular}{|c|c|c|c|}
\hline \multirow{2}{*}{ Kategori } & \multicolumn{3}{|c|}{ Distribusi } \\
\hline & Skor & Responden & Persentase (\%) \\
\hline Tidak Sekolah & 1 & 0 & 0 \\
\hline SD & 2 & 19 & 27,14 \\
\hline SMP & 3 & 21 & 30,00 \\
\hline SMA Sederajat & 4 & 25 & 35,72 \\
\hline D3/Sarjana & 5 & 5 & 7.14 \\
\hline Jumlah & & 70 & 100,00 \\
\hline
\end{tabular}

Berdasarkan Tabel 2. menunjukkan bahwa sebanyak 25 responden ( 35,72 persen) atau mayoritas responden telah menempuh pendidikan hingga tingkat SMA. Semakin tinggi tingkat pendidikan akan semakin mudah untuk berpikir rasional serta menangkap informasi baru termasuk dapat mempengaruhi seseorang dalam merespon sesuatu yang baru. Umur dalam kategori produktif, cenderung lebih mudah dalam menerima sesuatu inovasi baru dan lebih terbuka dengan kemajuan teknologi (Lionberger, 1960).

Tabel 3. Distribusi Responden Berdasarkan Pengalaman Pribadi

\begin{tabular}{lcccc}
\hline \multirow{2}{*}{ Kategori } & \multicolumn{4}{c}{ Distribusi } \\
\cline { 2 - 5 } & Lebar Interval & Skor & Responden & Persentase (\%) \\
\hline Sangat Rendah & $3,0-5,4$ & 1 & 5 & 7,14 \\
Rendah & $5,5-7,9$ & 2 & 10 & 14,29 \\
Sedang & $\mathbf{8 , 0}-\mathbf{1 0 , 4}$ & $\mathbf{3}$ & $\mathbf{2 8}$ & $\mathbf{4 0 , 0 0}$ \\
Tinggi & $10,5-12,9$ & 4 & 13 & 18,57 \\
Sangat Tinggi & $13,0-15,4$ & 5 & 14 & 20,00 \\
\hline & & & $\mathbf{7 0}$ & $\mathbf{1 0 0 , 0 0}$ \\
\hline
\end{tabular}

Berdasarkan pada Tabel 3. menunjukkan bahwapengalaman pribadi yang dimiliki masyarakat terkait urban farming pada kategori sedang dengan persentase $40 \%$.Pengalaman pribadi dalam hal ini yang berkaitan dengan pelatihan, sosialisasi serta pertemuan kelompok tani tentunya akan membuat responden lebih menguraikan masalah yang berkaitan dengan program urban farming. Tingkat pendidikan dapat mempengaruhi kemampuan berpikir, pendidikan juga membuat seseorang terdorong untuk ingin tahu, mencari pengalaman sehingga infornasi yang diterima akan menjadi pengetahuan (Dini, 2009).

berpengalaman dalam kegiatan urban farming. Azwar (2013) menyatakan bahwa apa yang telah dan sedang kita alami akan ikut membentuk dan mempengaruhi penghayatan kita terhadap stimulus sosial. 
Tabel 4. Distribusi Responden Berdasarkan Pengaruh Keluarga

\begin{tabular}{|c|c|c|c|c|}
\hline \multirow{2}{*}{ Kategori } & \multicolumn{4}{|c|}{ Distribusi } \\
\hline & Lebar Interval & Skor & Responden & Persentase $(\%)$ \\
\hline Sangat Rendah & $4,0-7,2$ & 1 & 1 & 1,43 \\
\hline Rendah & $7,3-10,5$ & 2 & 11 & 15,71 \\
\hline Biasa Saja/Cukup & $10,6-13,8$ & 3 & 18 & 25,71 \\
\hline Tinggi & $13,9-17,1$ & 4 & 34 & 48,57 \\
\hline Sangat Tinggi & $17,2-20,4$ & 5 & 6 & 8,58 \\
\hline \multicolumn{3}{|c|}{ Jumlah } & 70 & 100,00 \\
\hline
\end{tabular}

Berdasarkan data pada Tabel 4. pengaruh keluarga mayoritas termasuk kategori tinggi dengan persentase $48,57 \%$. Peran dari keluarga terhadap program urban farming adalah sebagai pemberi masukan dan faktor dalam pengambilan keputusan masyarakat terkait program. Menurut
Friedman (1998), menyatakan bahwa keluarga berfungsi sebagai sistem pendukung bagi anggotanya. Anggota keluarga memandang bahwa orang yang bersifat mendukung, selalu siap memberikan pertolongan dan bantuan jika diperlukan.

Tabel 5. Distribusi Responden Berdasarkan Kelompok Acuan

\begin{tabular}{lcccc}
\hline \multirow{2}{*}{ Kategori } & \multicolumn{4}{c}{ Distribusi } \\
\cline { 2 - 5 } & Lebar Interval & Skor & Responden & Persentase (\%) \\
\hline Sangat Tidak Berperan & $8,0-14,4$ & 1 & 0 & 0 \\
Tidak Berperan & $14,5-20,9$ & 2 & 17 & 24,29 \\
Biasa Saja/Cukup & $\mathbf{2 1 , 0 - 2 7 , 4}$ & $\mathbf{3}$ & $\mathbf{2 7}$ & $\mathbf{3 8 , 5 7}$ \\
Berperan & $27,5-33,9$ & 4 & 15 & 21,43 \\
Sangat Berperan & $34,0-40,4$ & 5 & 11 & 15,71 \\
\hline & & & $\mathbf{7 0}$ & $\mathbf{1 0 0 , 0 0}$ \\
\hline
\end{tabular}

Berdasarkan Tabel5.mayoritas pengaruh kelompok acuan adalah biasa saja/cukup.Hal ini dapat diketahui dari 70 responden, sebanyak 27 $(38,57 \%)$ responden menyatakan biasa saja/cukup. Masyarakat dalam melakukan kegiatan urban

Tabel 6. Distribusi Responden Berdasarkan Terpaan Media Massa farming seringkali menemui kendala, sehingga pada saat itu mereka akan meminta bantuan atau saran dari kelompok acuan mereka, seperti PPL, ketua kelompok tani dan rekan sesama petani.

\begin{tabular}{|c|c|c|c|c|}
\hline \multirow[b]{2}{*}{ Kategori } & \multicolumn{4}{|c|}{ Distribusi } \\
\hline & $\begin{array}{c}\text { Lebar } \\
\text { Interval }\end{array}$ & Skor & Responden & $\begin{array}{c}\text { Persentase } \\
(\%)\end{array}$ \\
\hline Sangat Tidak Berperan & $8,0-14,4$ & 1 & 0 & 0 \\
\hline Tidak Berperan & $14,5-20,9$ & 2 & 17 & 24,29 \\
\hline Biasa Saja/Cukup & $21,0-27,4$ & 3 & 27 & 38,57 \\
\hline Berperan & $27,5-33,9$ & 4 & 15 & 21,43 \\
\hline Sangat Berperan & $34,0-40,4$ & 5 & 11 & 15,71 \\
\hline & & & 70 & 100,00 \\
\hline
\end{tabular}

Berdasarkan data pada Tabel 6. dapat dilihat mayoritas responden atau sebanyak 28 responden (40,00 persen) memiliki tingkat terpaan media massa pada kategori sedang. Kebutuhan akan informasi bagi masyarakat, membuat mereka banyak mencari informasi dari berbagai media, 
sehingga dapat memudahkan masyarakat dalam mencari informasi khususnya terkait urban farming. Azwar (2013) menyatakan bahwa, sebagai sarana komunikasi, berbagai bentuk

Tabel 7.Distribusi Responden Berdasarkan Terpaan Media Massa media massa seperti televisi, radio, surat kabar, dll mempunyai pengaruh besar dalam pembentukan opini dan kepercayaan orang.

\begin{tabular}{lcccc}
\hline \multirow{2}{*}{ Kategori } & \multicolumn{4}{c}{ Distribusi } \\
\cline { 2 - 5 } & Lebar Interval & Skor & Responden & Persentase (\%) \\
\hline Sangat Rendah & $4,0-7,2$ & 1 & 1 & 1,43 \\
Rendah & $7,3-10,5$ & 2 & 7 & 10,00 \\
Sedang & $10,6-13,8$ & 3 & 24 & 34,29 \\
Tinggi & $\mathbf{1 3 , 9 - 1 7 , 1}$ & $\mathbf{4}$ & $\mathbf{2 6}$ & $\mathbf{3 7 , 1 4}$ \\
Sangat Tinggi & $17,2-20,4$ & 5 & 12 & 17,14 \\
\hline & & & $\mathbf{7 0}$ & $\mathbf{1 0 0 , 0 0}$ \\
\hline
\end{tabular}

Berdasarkan data pada Tabel 7.dapat diketahui pengaruh budaya terkait proram urban faming mayoritas tergolong tinggi dengan persentase $37,14 \%$. Kebudayaan dalam penelitian termasuk dalam kategori tinggi, yang dapat dilihat dari budaya gotong royong, kebudayaan akanback to nature, serta kebiasaan yang dilakukan masyarakat dalam era modern saat ini yaitu penggunaan internet maupun telepon genggam. Kebudayaan terdiri dari segala sesuatu yang dipelajari dari pola-pola perilaku yang normatif. Artinya, mencakup segala cara-cara atau pola-pola berpikir, merasakan dan bertindak (Tumanggor, 2010).

\section{Sikap Masyarakat terhadap Program Peningkatan dan Pengembangan Pertanian Perkotaan (Urban Farming)}

Sikap masyarakat terhadap urban farming di Kecamatan Jebres merupakan respon masyarakat mengenai program urban farming yang sedang berjalan di Kecamatan Jebres, penilaian tersebut meliputi tujuan program, pelaksanaan program dan hasil program.Sikap masyarakat dalam penelitian ini dikategorikan menjadi sangat tidak setuju, tidak setuju, netral, setuju, dan sangat setuju.

Tabel 8. Distribusi Responden Berdasarkan Sikap terhadap Tujuan Program

\begin{tabular}{|c|c|c|c|c|}
\hline \multirow{2}{*}{ Kategori } & \multicolumn{4}{|c|}{ Distribusi } \\
\hline & Lebar Interval & Skor & Responden & Presentase (\%) \\
\hline Sangat Tidak Setuju & $12,0-21,6$ & 1 & 0 & 0 \\
\hline Tidak Setuju & $21,7-31,3$ & 2 & 4 & 5,71 \\
\hline Netral & $31,4-41,0$ & 3 & 21 & 30,00 \\
\hline Setuju & $41,1-50,7$ & 4 & 39 & 55,72 \\
\hline Sangat Setuju & $50,8-60,4$ & 5 & 6 & 8,57 \\
\hline \multicolumn{3}{|l|}{ Jumlah } & 70 & 100,00 \\
\hline $\begin{array}{l}\text { Berdasarkan data pada } \\
\text { 8.menunjukkan bahwa sebanyak } 39 \mathrm{r} \\
(55,72 \%) \text { menyatakan setuju dengar } \\
\text { program urban farming. Hal ini men } \\
\text { bahwa mayoritas responden setuju deng } \\
\text { program urban farming, artinya urban }\end{array}$ & $\begin{aligned} \text { Tabel } & \text { yang } \\
\text { responden } & \text { farmi } \\
\text { in tujuan } & \text { dari } \\
\text { nunjukkan } & \text { dapat } \\
\text { gan tujuan } & \text { dapat } \\
n \text { farming } & \text { Keca }\end{aligned}$ & \multicolumn{3}{|c|}{$\begin{array}{l}\text { yang tidak setuju dengan tujuan program urban } \\
\text { farming yaitu sebesar } 5,71 \text { persen atau } 4 \text { responden } \\
\text { dari kelompok tani yang tidak aktif, namun } \\
\text { dapat dipastikan bahwa program urban farming } \\
\text { dapat diterima dengan baik oleh masyarakat di } \\
\text { Kecamatan Jebres. }\end{array}$} \\
\hline
\end{tabular}

memiliki tujuan yang dinilai oleh responden sesuai dengan kebutuhan mereka. Meskipun masih ada 
Tabel 9. Distribusi Responden Berdasarkan Sikap terhadap Pelaksanaan Program

\begin{tabular}{lcccc}
\hline \multirow{2}{*}{ Kategori } & \multicolumn{4}{c}{ Distribusi } \\
\cline { 2 - 5 } & Lebar Interval & Skor & Responden & Presentase (\%) \\
\hline Sangat Tidak Setuju & $6,0-10,8$ & 1 & 0 & 0 \\
Tidak Setuju & $10,9-15,7$ & 2 & 3 & 4,29 \\
Netral & $\mathbf{1 5 , 8 - 2 0 , 6}$ & $\mathbf{3}$ & $\mathbf{3 6}$ & $\mathbf{5 1 , 4 3}$ \\
Setuju & $20,7-25,5$ & 4 & 26 & 37,14 \\
Sangat Setuju & $25,6-30,4$ & 5 & 5 & 7,14 \\
\hline & & & $\mathbf{7 0}$ & $\mathbf{1 0 0 , 0 0}$ \\
\hline
\end{tabular}

Berdasarkan data pada Tabel 9.dapat dilihat jumlah distribusi responden berdasarkan sikap terhadap pelaksanaan urban farmingmenunjukkan bahwa sebanyak 36 responden (51,43 persen) menyatakan netral dengan pelaksanaan urban farming.Masyarakat menilai bahwa pelaksanaan Tabel 10. Distribusi Responden Berdasarkan Sikap terhadap Hasil Program

\begin{tabular}{lcccc}
\hline \multirow{2}{*}{ Kategori } & \multicolumn{4}{c}{ Distribusi } \\
\cline { 2 - 5 } & Lebar Interval & Skor & Responden & Presentase (\%) \\
\hline Sangat Tidak Setuju & $6,0-10,8$ & 1 & 0 & 0 \\
Tidak Setuju & $10,9-15,7$ & 2 & 3 & 4,29 \\
Netral & $15,8-20,6$ & 3 & 36 & 51,43 \\
Setuju & $20,7-25,5$ & 4 & 26 & 37,14 \\
Sangat Setuju & $25,6-30,4$ & 5 & 5 & 7,14 \\
\hline & & & $\mathbf{7 0}$ & $\mathbf{1 0 0 , 0 0}$ \\
\hline
\end{tabular}

Berdasarkan Tabel 10. Menunjukkan bahwa sikap masyarakat terhadap hasil dari program urban famringmayoritas termasuk dalam kategori setuju dengan persentase 42,86 persen. Hal ini telah dirasakan oleh masyarakat yang ada di RW 37 Mojosongo, Kecamatan Jebres.Daerah mereka menjadi terkenal dikalangan luar daerah dengan sebutan "Kampung Sayur" karena hampir satu RW menerapkan urban farming dengan sistem tanam vertikultur, maupun hidroponik.Hasil dari program urban farming juga dapat mempererat hubungan antar masyarakat dalam berorginasasi.

Hubungan antara Faktor-Faktor Pembentuk Sikap dengan Sikap Masyarakat terhadap Program Peningkatan dan Pengembangan Pertanian Perkotaan (Urban Farming)

Analisis yang digunakan untuk mengetahui hubungan antara faktor-faktor pembentuk sikap dengan sikap masyarakat program urban farming dibeberapa daerah belum merata khususnya daerah yang sekarang kelompok taninya tidak aktif.Winkel (1987) menyatakan bahwa sikap adalah kecenderungan seseorang untuk menerima atau menolak suatu objek berdasarkan penilaian terhadap objek tersebut. terhadap program peningkatan dan pengembangan pertanian perkotaan (urban farming) menggunakan uji korelasi Rank Kendall yang dihitung dengan program SPSS versi 20 for windows. Untuk mengetahui tingkat signifikansi dengan membandingkan besarnya nilainya $t_{\text {hitung }}$ dan $t_{\text {tabel }}$ dengan tingkat kepercayaan 95\% ( $\alpha$ $=0,05)$.Apabila $t_{\text {hitung }} \geq t_{\text {tabel }}$ maka Ho ditolak, artinya terdapat hubungan yang signifikan antara faktor pembentuk sikap dengan sikap masyarakat terhadap program peningkatan dan pengembangan pertanian perkotaan (Urban farming) di Kecamatan Jebres Kota Surakarta. Sebaliknya, apabila $\mathrm{t}_{\text {hitung }}<$ $\mathrm{t}_{\text {tabel }}$ maka $\mathrm{H}_{0}$ diterima, artinya tidak ada hubungan yang signifikan antara faktor pembentuk sikap dengan sikap masyarakat terhadap program peningkatan dan pengembangan pertanian perkotaan (Urban farming) di Kecamatan Jebres Kota Surakarta. 
Tabel 11. Uji Rank Kendall Antara Faktor Pembentuk Sikap dengan Sikap Masyarakat terhadap Program Urban farming di Kecamatan Jebres Kota Surakarta

\begin{tabular}{|c|c|c|c|c|c|c|c|c|c|c|c|c|}
\hline \multirow{2}{*}{$\mathbf{X}$} & \multicolumn{3}{|c|}{ Tujuan Program (Y1) } & \multicolumn{3}{|c|}{ Pelaksanaan Program (Y2) } & \multicolumn{3}{|c|}{ Hasil Program (Y3) } & \multicolumn{3}{|c|}{ Sikap Total (Ytot) } \\
\hline & $\tau$ & Sig. & t hit & $\tau$ & Sig. & t hit & $\tau$ & Sig. & t hit & $\tau$ & Sig. & t hit \\
\hline $\mathrm{X} 1.1$ & 0,137 & 0,140 & 1.140 & 0,168 & 0,076 & 1.405 & 0,130 & 0,169 & 1.081 & 0,137 & 0,135 & 1.140 \\
\hline $\mathrm{X} 1.2$ & 0,460 & 0.627 & 4.272 & 0,112 & 0,242 & 0.929 & 0,047 & 0,621 & 0.388 & 0,048 & 0,608 & 0.396 \\
\hline $\mathrm{X} 2$ & $0,448^{* *}$ & 0,000 & 4.132 & $0,372^{* *}$ & 0,000 & 3.305 & $0,439^{* *}$ & 0,000 & 4.029 & $0,458^{* *}$ & 0,000 & 4.248 \\
\hline $\mathrm{X} 3$ & $0,206^{*}$ & 0,018 & 1.736 & $0,178^{*}$ & 0,045 & 1.492 & 0,129 & 0,148 & 1.073 & $0,204^{*}$ & 0,018 & 2.201 \\
\hline $\mathrm{X} 4$ & $0,476^{* *}$ & 0,000 & 4.463 & $0,349^{* *}$ & 0,000 & 3.071 & $0,408^{* *}$ & 0,000 & 3.685 & $0,471^{* *}$ & 0,000 & 4.403 \\
\hline $\mathrm{X} 5$ & $0,418^{* *}$ & 0,000 & 3.794 & $0,363^{* *}$ & 0,000 & 3.212 & $0,320^{* *}$ & 0,000 & 2.785 & $0,416^{* *}$ & 0,000 & 3.772 \\
\hline X6 & $0,337^{* *}$ & 0,000 & 2.952 & $0,283^{* *}$ & 0,001 & 2.433 & $0,332^{* *}$ & 0,000 & 2.902 & $0,344^{* *}$ & 0,000 & 3.021 \\
\hline
\end{tabular}

Keterangan:

$\mathrm{X} 1.1$ : Umur

X2.1 : Pendidikan

X2 : Pengalaman Pribadi

X3 : Pengaruh Keluarga

X4 : Kelompok Acuan

X5 : Terpaan Media Massa

X6 : Budaya

Umur tidak memiliki hubungan yang signifikan dengan sikap masyarakat terhadap program urban farming. Hubungan yang tidak signifikan antara umur dengan sikap masyarakat terhadap program urban farming menunjukkan bahwa responden dengan usia produktifmaupun non produktif tidak berhubungan dengan sikap masyarakat terhadap program urban farming. Artinya program urban farming dapat disikapi baik dan dapat diterima pada berbagai golongan umur responden. Hal ini tidak sesuai dengan pernyataan semakin bertambah umur maka penalaran dan pengetahuan semakin bertambah dan sikap terhadap suatu objek dapat sangat kuat (Walgito, 2003).

Tingkat pendidikan formal tidak memiliki hubungan yang signifikan dengan sikap masyarakat terhadap program urban farming. Tingkat pendidikan yang tinggi tentunya akan membuat seseorang semakin baik dalam menerima suatu inovasi atau program pemerintah. Namun, pada penelitian kali ini tingkat pendidikan formal tidak berpengaruh pada sikap masyarakat terhadap program urban farming. Hal ini bertentangan dengan pernyataan Azwar (1997) bahwa lembaga pendidikan sebagai suatu sistem mempunyai pengaruh dalam pembentukan sikap individu. Pemahaman akan baik dan buruk, garis pemisah antara sesuatu yang boleh dan tidak boleh dilakukan diperoleh dari pendidikan.

Pengalaman pribadimemiliki hubungan yang sangat signifikan dengan sikap masyarakat terhadap program urban farming.Hubungan yang sangat signifikan ini dapat terjadi karena responden yang memiliki banyak pengalaman dalam bidang pertanian sehingga responden akan sangat berpengalaman dalam urusan pertanian dan mereka juga cenderung lebih paham mana yang baik untuk mereka, sehingga saat ada program pemerintah yang menurut responden dapat meningkatkan kesejahteraan hidupnya, mereka akan memutuskan untuk menjalankan program tersebut.Hal ini sesuai dengan pernyataan Rahayuningsih (2008) yaitu semakin banyak seseorang memiliki pengalaman terhadap sesuatu hal maka akan mempengaruhi sikap seseorang terhadap suatu hal tersebut.

Pengaruh keluarga memiliki hubungan yang signifikan dengan sikap masyarakat terhadap program urban farming.Keluarga berfungsi sebagai sistem pendukung bagi anggotanya. Anggota keluarga memandang bahwa keluarga merupakan orang yang bersifat mendukung dan selalu siap memberikan pertolongan dan bantuan jika diperlukan.Hal ini sesuai dengan yang diutarakan olehSchiffman dan Kanuk (1994) yaitu keluarga merupakan sumber pengaruh yang sangat penting dalam pembentukan sikap karena 
keluarga mengajarkan mengenai nilai dasar dan kepercayaan. Sikap positif atau negatif bisa dibentuk berdasarkan informasi, anjuran atau larangan yang disampaikan melalui kata-kata. Sikap memang bisa dibentuk atau diubah melalui kontak dengan orang-orang yang diteladani.

Kelompok acuan memiliki hubungan yang sangat signifikan dengan sikap masyarakat terhadap program urban farming.Penyuluh sebagai kelompok acuan bagi masyarakat berperan penting dalam menyampaikan informasi utama mengenai urban farming kepada ketua kelompok tani, kemudian ketua kelompok tani yang mendapatkan informasi tersebut menyampaikannya lagi kepada anggotanya. Hal ini sesuai dengan pernyataan Schiffman dan Kanuk (1994) bahwa kelompok acuan merupakan seorang individu atau sekelompok orang yang secara nyata dapat mempengaruhi keyakinan, nilai sikap dan perilaku seseorang. Kelompok acuan mempunyai pengaruh langsung (tatap muka) atau pengaruh tidak langsung terhadap sikap atau perilaku seseorang. Konsep dasar ini dapat memberikan perspektif untuk memahami kepercayaan, sikap dan perilaku seseorang.

Terpaan media massa memiliki hubungan yang sangat signifikan dengan sikap masyarakat terhadap program urban farming.Sebagai sarana komunikasi, berbagai bentuk media massa seperti televisi, radio, surat kabar, majalah, dll mempunyai pengaruh besar dalam pembentukan opini dan kepercayaan orang. Penyuluh maupun masyarakat yang ada di Kecamatan Jebres sering menggunakan media massa untuk mencari informasi terkait urban farming. Hal ini sesuai dengan pernyataan Schiffman dan Kanuk (1994) Komunikasi media massa sangat penting dalam memberikan sumber informasi dan berpengaruh dalam pembentukan sikap seseorang, media massa merupakan sumber informasi utama dalam memaparkan ide, produk, opini, dll.

Pengaruh budaya memiliki hubungan yang sangat signifikan dengan sikap masyarakat terhadap program urban farming.Budaya merupakan tradisi/keinovatifan yang ada di masyarakat setempat. Seperti di Kecamatan Jebres tradisi diwilayahnya pun masih kental seperti gotong royong untuk mempererat hubungan antar sesama masyarakat. Keinovatifanpun juga selalu berkembang sesuai dengan perkembangan jaman seperti kesadaran akan back to nature, penggunaan internet serta telepon genggam sebagai sarana berkomunikasi sehingga masyarakat memiliki hubungan yang kuat dengan budaya yang dapat mempengaruhi sikap mereka terhadap sesuatu hal. Tanpa disadari kebudayaan telah menanamkan garis pengaruh sikap terhadap berbagai masalah. Kebudayaan merupakan salah satu faktor yang dapat mempengaruhi pembentukkan pribadi seseorang.

\section{KESIMPULANDAN SARAN}

\section{Kesimpulan}

Faktor-faktor pembentuk sikap masyarakat terhadap program Peningkatan dan Pengembangan Pertanian Perkotaan (Urban Farming) di Kecamatan Jebres yaitu: Karakteristik individu masyarakat untuk umur antara 46 - 55 tahun dan untuk tingkat pendidikan telah menempuh hingga jenjang pendidikan SMA. Pengalaman pribadi termasuk dalam kategori sedang. Pengaruh keluarga termasuk dalam kategori tinggi. Kelompok acuan termasuk dalam kategori cukup berperan. Terpaan media massa termasuk dalam kategori sedang. Kebudayaan dalam kategori tinggi yaitu budaya gotong royong, kesadaran back to nature hingga kebiasaan responden dalam menggunakan internet.Sikap masyarakat terhadap program urban farming di Kecamatan Jebres yaitu: tujuan program urban farming dalam kategori setuju, pelaksanaan program urban farming dalam kategori netral atau sedang dan hasil program urban farming dalam kategori setuju.Hasil uji analisis hubungan antara Faktor-faktor pembentuk sikap masyarakat terhadap program Peningkatan dan Pengembangan Pertanian Perkotaan (Urban Farming) yaitu: Tidak terdapat hubungan yang signifikan antara karakteristik individu yaitu tingkat umur dan tingkat pendidikan, Terdapat hubungan yang signifikan antara pengalaman pribadi, pengaruh keluarga, kelompok acuan, terpaan media massa serta budaya dengan sikap masyarakat terhadap program urban farming.

\section{Saran}

Berdasarkan hasil penelitian yang telah dilakukan, maka saran yang dapat diberikan adalahkelompok acuan yang memiliki pengaruh dalam keberhasilan program dalam hal ini adalah 
penyuluh dan ketua kelompok tani diharapkan dapat mempertahankan antusias masyarakat terkait urban farming dengan cara mengadakan kegiatan pelatihan maupun pertemuan secara rutin terkait program urban farming sehingga dapat menambah wawasan dan masyarakat menjadi lebih paham mengenai program urban farming, masyarakat diharapkan dapat terus meningkatkan pengalaman pribadi mereka khususnya terkait program urban farming dengan cara mengikuti pertemuan kelompok tani, sosialisasi, pelatihan maupun penyuluhan agar masyarakat mendapatkan informasi dan dapat memecahkan masalah mereka terkait bidang pertanian, program pertanian perkotaan atau urban farming ini termasuk program yang dapat menyejahterakan masyarakat serta dapat memberikan keuntungan sosial maupun ekonomi bagi masyarakat, maka dari itu perlu menjadi perhatian bagi Pemerintah Kota Surakarta khususnya dalam pemberian bantuan yang sesuai dengan kebutuhan masyarakat saat ini yaitu lebih pada pemberian tanaman hortikultura dalam pot serta kolam untuk penangkaran ikan lele.

\section{DAFTAR PUSTAKA}

Almalifah, Siti Mahmodha. 2005. Analisis Karakteristik Individu dan Karakteristik Organisasi terhadap Pengembangan karir Pegawai di Kanwil Bea Dan Cukai Surabaya. Tesis.

Azwar, S. 2013. Sikap Manusia Teori dan Pengukurannya. Yogyakarta: Pustaka Pelajar Offset.

Departemen Pertanian. 2006. Petunjuk Pelaksanaan Program Peningkatan dan Pengembangan Pertanian Perkotaan di Kota Surakarta. Departemen Pertanian Kota Surakarta.

Friedman, 1998.Keperawatan Keluarga. Jakarta: EGC.

Hawkins et al. (1999).Consumer Behavior. New York: Mc Graw Hill.

Kusrini, Nini, Siti Amanah, Anna Fatchiya. 2013. Sikap Masyarakat terhadap Program Pengembangan Desa Pesisir Tangguh di
Teluknaga, Tangerang, Banten.Jurnal Sosio Konsepsia.

Laepple, Doris dan Trevor Donnellan. 2008. National Organic Conference. Rural Economy Research Centre (RERC), Teagasc, Athenry.

Lionberger, Herbert F.1960. Adoption of New Ideas and Practices. U.S.A: The Iowa State University Press.

Odongo J. A. dan Muhua G. O. 2015.Modelling the Relationship between Farmer's Attitude towards Farming and Farm Practices: a Case Study of Smallholder Farmers in Tanzania.European Scientific Journal.

Okoro, Enyinnaya, Iwueke Nyainbau Tarinabo, et al. 2017. Environmental and Economic Perception of Urban Farming in $A b a$, Nigeria.International Journal of Environmental Chemistry.

Schiffman, L.G dan Kanuk, L.L. 1994.Consumer Behavior. $5^{\text {th }}$ Ed. New Jersey: Prentice Hall.

Siegel, S. 1994. Statistik Non Parametrik. Jakarta: Gramedia.

Singarimbun, M dan S. Effendi. 1995. Metode Penelitian Survey. Jakarta: LP3ES.

Sugiyono. 2013. Metode Penelitian Kuantitatif Kualitatif dan R\&D. Bandung: Alfabeta.

Tumanggor, Rusmin.,et al. 2010. Ilmu Sosial dan Budaya Dasar. Jakarta: Kencana.

UNDP 1996. Urban Agriculture: Food, Jobs and sustainable cities. United Nations Development Program.Publication Series for Habitat $l l$. New York: UNDP.

Walgito, Bimo. 2003. Pengantar Psikologi Umum. Yogyakarta: ANDI.

Widyawati, N. 2013.Urban farming Gaya Bertani Spesifik Kota. Yogyakarta: Penerbit Andi. 